\title{
Do Career Demands and Career Choices Always Coincide? A Matching Perspective Based on Career Anchors and Job Characteristics
}

\author{
Hong Chen $1,2, * \mathbb{D}$, Yujie Wang ${ }^{3}$ and Yunqiao Ding ${ }^{3}$ \\ 1 School of Business, Jiangnan University, Wuxi 214122, China \\ 2 Institute of National Security and Green Development, Jiangnan University, Wuxi 214122, China \\ 3 School of Economics and Management, China University of Mining and Technology, Xuzhou 221116, China; \\ wangyujiesx@163.com (Y.W.); Dingyunqiao@163.com (Y.D.) \\ * Correspondence: hongchenxz@163.com; Tel.: +86-13372210769
}

Citation: Chen, H.; Wang, Y.; Ding, Y. Do Career Demands and Career Choices Always Coincide? A Matching Perspective Based on Career Anchors and Job Characteristics. Sustainability 2021, 13, 11273. https:// doi.org/10.3390/su132011273

Academic Editor: Ermanno C. Tortia

Received: 2 September 2021

Accepted: 7 October 2021

Published: 13 October 2021

Publisher's Note: MDPI stays neutral with regard to jurisdictional claims in published maps and institutional affiliations.

Copyright: () 2021 by the authors. Licensee MDPI, Basel, Switzerland. This article is an open access article distributed under the terms and conditions of the Creative Commons Attribution (CC BY) license (https:// creativecommons.org/licenses/by/ $4.0 /)$.

\begin{abstract}
Career choice is an important behavior for people wanting to develop their social life and is a key link to doing so. The matching of career choice with an individual's real work demands will have a significant impact on the development of individuals, organizations, and society. However, at this stage, there are few studies on this matching situation. From the perspective of the matching of career anchors and job characteristics, this study explored the distribution and different characteristics of employees' career demands and their career choices through a survey of 407 employees, and further discussed the matching status of these. The results of the study are as follows: (1) Individual career demands (career anchors) presented three attributes: single, multiple, and unclear. Among the single career anchor types, life anchors had the largest proportion, while among multiple career anchor individuals, individuals with both challenge anchors and service anchors accounted for the majority. (2) Individual career demands (career anchors) were significantly different across most demographic variables and organizational/work variables. (3) Deviations between employees' career demands and their career choices seemed to be a common phenomenon, with the highest degree of fit $(62.79 \%)$ with the entrepreneurial creativity anchor and the lowest degree of fit $(21.28 \%)$ with the lifestyle anchor. In addition, in an analysis of three job fit characteristics, the entrepreneurial creativity anchor had a significant preference for managerial characteristics, whereas the challenge anchor had a significant preference for technological characteristics. The degrees of fit of the other anchors were characterized by the frequency of 'right suboptimal fit' being larger than that of 'left suboptimal fit'. In other words, a specific career anchor had a significant preference for job characteristics matched by the right career anchor, with the midpoint of the career anchor octagon model defining the angle of observation. This study provides a reference for human resource management departments and for employees' recognition and planning of career anchors.
\end{abstract}

Keywords: career choices; true demand; career anchor; job characteristics; degree of fit

\section{Introduction}

Career choice is the selection and determination of the type and direction of one's employment, which is a key part of an individual's development. Choosing a career that is consistent with one's own aspirations, characteristics and talents will have an important impact on the development of individuals, organizations, and society [1,2]. However, the severe employment situation and enormous employment pressure have led many employment groups to engage in the short-sighted employment behavior of "employment before career choices", resulting in abnormally high turnover, rejection by enterprises and distorted allocation of human resources [3,4]. Worse still, this blind employment behavior not only makes individuals' career self-perceptions, career talents and job positions diverge to different degrees-which hinders the self-fulfillment of individuals' careers-but also 
brings a certain degree of negative impact on organizational performance $[5,6]$. Therefore, clarifying the match between career demands and career choices in the current workplace, improving the match between individuals and jobs, and to achieving a win-win situation, have become issues that employees and organizations need to pay attention to together.

What variable can be used to measure employees' career intentions or career demands? Schein (1978) defined this variable as a career anchor, which indicates the one element in our self-concept that we will not give up, even when forced to make a difficult choice [7]. Since then, career anchors have received widespread attention from scholars, and many scholars have used career anchors to characterize career aspirations or career intentions and have conducted a lot of theoretical and empirical studies based on career anchors [8,9]. Job characteristics refer to the general and specific attributes of a job group, which are a reflection of the characteristics of an individual current job. At present, scholars have mostly adopted such job characteristics to characterize specific career choices and have conducted a large number of related studies based on these [10,11]. A systematic review of the relevant literature shows that academic research on the relationship between career anchors and job characteristics has mostly focused on the impact of the match and consistency between the two on individual job outcome variables [12-14]; for example, Medsker \& O'Connor (2015) found that a good fit between career anchor and job characteristics greatly strengthened employees' work motivation [15]. In addition, Ghalavandi (2012) claimed that consistency in these two factors had a significant influence on turnover intention, career success, and organizational commitment [16]. However, these studies have mostly studied the correlation between the variables from a macro perspective, and few scholars have conducted in-depth analyses of the differences in the matching between different anchor types and job characteristics, thus making it difficult to creatively propose relevant management strategies from a micro perspective.

Based on the aforementioned discussion, and from the perspective of the degree of fit between career anchor and job characteristics, various samples were investigated to analyze the variation of different career anchors on statistical variables, to compute the degrees of fit of different career anchors and job characteristics, and to discuss more deeply the preferences of specific career anchors with regards to their degrees of fit with job characteristics. Generally, exploring the degree of fit between the career anchor and job characteristics of various samples has been considered a supplement to career anchor theory; the micro perspective extends this research scope. Besides, it was necessary to clarify the degree of fit between different career anchors and job characteristics because of its significance for solving workplace problems, attaining employees' self-fulfillment of occupational values, and developing long-term organizational performance.

The innovations of this study include: (1) studying the matching between career anchors and job characteristics from the perspective of micro-matching, which is a supplement to the theory of career anchors and makes up for the shortage of existing research perspectives; (2) clarifying the matching relationship and preference relationship between different career anchors and job characteristics, which helps to "prescribe the right remedy" for problems in the workplace and provides a reference for the organization's human resource management department and employees' career anchor recognition and planning.

\section{Literature Review}

\subsection{Career Anchor Theory}

Career anchor theory, also known as career orientation theory, is a theory of career choice that starts with the individual and was first developed by Professor Schein in his study of students' career development processes. This theory suggests that a career anchor is when a person has to make a choice and he or she will not give up the vital things or values in the career that are important to him or her. In layman's terms, a career anchor is actually the center around which people choose and develop their careers-a self-intended career orientation. In terms of the dimensions of career anchors, Professor Schein's first theory of career anchors classified them into five categories [7], namely, technical/functional 
competence anchors, managerial competence anchors, security and stability anchors, autonomy and in-dependence anchors, and entrepreneurial creativity anchors. This was later refined and expanded to include three types of anchors: service and dedication anchors, challenge anchors, and lifestyle anchors [17]. Since then, scholars have conducted a series of exploratory studies on this basis $[18,19]$. Several scholars have researched theories related to career anchors; for example, Feldman \& Bolino (1996) modified and developed Professor Schein's model of career anchors and proposed the hypothesis of multiple career anchors, suggesting that career anchors can be classified as talent-based (technical anchors, management anchors, entrepreneurial creativity anchors) and need-based (security and stability anchors, autonomy and independence anchors, lifestyle anchors); in addition, the octagonal theory of career anchors was creatively proposed based on Holland's career aptitude model [20] (Figure 1) It was further pointed out that in the octagonal model of career anchors, the compatibility between adjacent career anchors is the highest, while those on the diagonal are the least compatible and often mutually exclusive. This theory also occupies an important place in the field of career anchors [9,12,21]. Some other scholars have studied the relationship between career anchors and individual characteristics and organizational variables, such as Chang et al. (2020), who studied the relationship between career anchors and individual traits-this study demonstrated differences in the career anchors of information technology/information system (IT/IS) personnel rooted in different cultures; the guanxi culture had a different effect on each career anchor [22]. Gubler et al. (2015) found that career anchors influence individual career trajectories through job satisfaction and organizational commitment, with management anchors and life anchors being the most significant [23]. In general, as studies on career anchor theory have systematically elaborated the concept and types of career anchors and conducted in-depth analysis on the relationship between career anchors and career choicesand job satisfaction, career anchor theory has been widely used in the fields of career planning, employee recruitment and selection, and organizational career development management [24,25]. Therefore, the career anchor octagon theory was chosen in this study to explore the fit between career anchors and job characteristics.

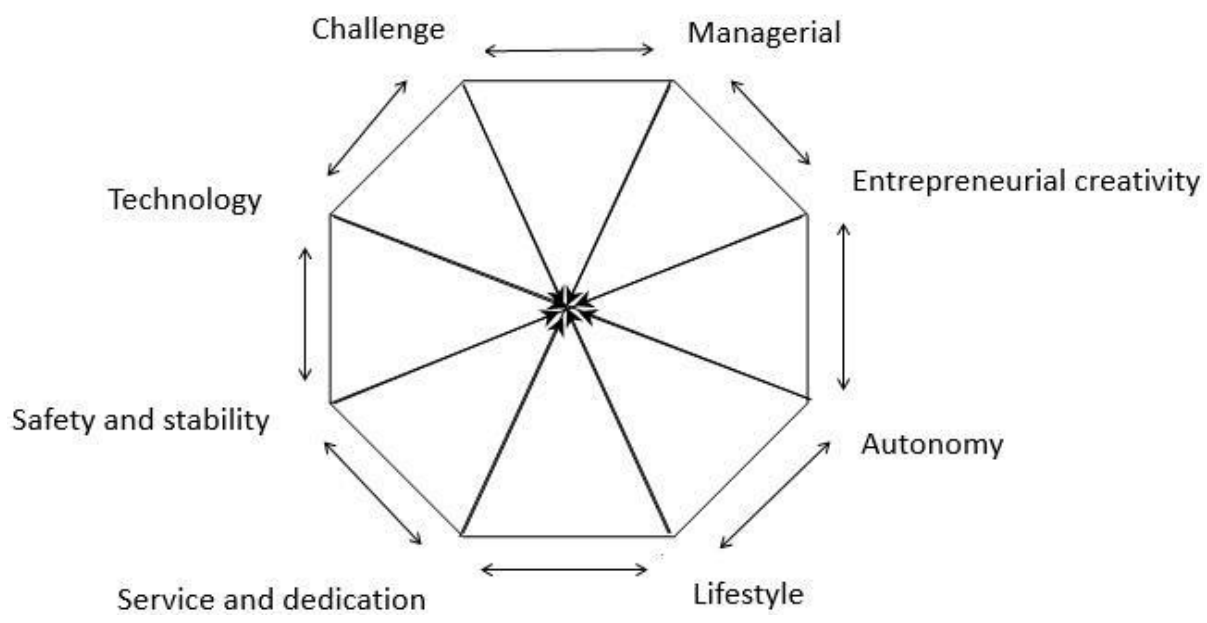

Figure 1. Career anchor octagon model.

\subsection{Person-Job Fit Theory}

Person-job fit (P-J fit) is a component of the Person-environment fit ( $\mathrm{P}-\mathrm{E}$ fit) theory and refers to the fit between individual capabilities and job position requirements [26]. P-E fit theory was produced on the basis of behavioral interaction theory, which claimed that behavior was a function of individuals and the environment, and that consistency between personal traits and the environment would promote positive results. The core of $\mathrm{P}-\mathrm{J}$ fit was to ensure the maximal usage of each employee and to satisfy employees' occupational demands. To researchers and managers, improving P-J fit was a powerful measure to raise employees job satisfaction and performance and to promote the long-term development 
of the organization. Current research on P-J fit has mostly been focused on the human resource optimization allocation model based on human-post matching $[27,28]$, which was mainly carried out through model construction and analysis to guide human resource management problems in practice-elaborating the importance of person-job matching and proposing specific countermeasures to achieve it [29]. Chen, Hsu, and Wang (2013) considered the different opinions of employers on P-J fit, person-organization fit, and Guanxi in their recruitment process, combining both Chinese and Western perspectives. They found that P-J fit was the most important factor influencing employers' recruitment decisions [30]. Xin et al. (2019) investigated the mediating effects of demands-abilities fit and needs-supplies fit in the relationship between career exploration and career satisfaction and compared the mediating effects of these two types of person-job fit. They found that both demands-abilities fit and needs-supplies fit mediated the relationship between career exploration and career satisfaction, and that needs-supplies fit has a greater mediating effect [31]. In general, P-J fit was measured using a P-J fit scale, which measured the degree of fit between individual capability, technology, and experience and their job characteristics, and these personality traits were measured by self-reporting [32,33]. In this study, the degree of fit between career anchor and job characteristics was chosen to study P-J fit, whereas the career anchor variable was found to be more representative in measuring individual capability and technology levels.

\section{Method}

\subsection{Variable Measurement}

The main purpose of this research was to explore the distribution characteristics and difference characteristics of employees' career demands and their career choices, and further discuss the match between the two. Based on the previous analysis, this study used career anchors to represent individual career demands, and real job characteristics to represent individual career choices. In terms of research methods, this study adopted a questionnaire survey. In terms of specific measurement scales, the measurement scales of this study were mainly divided into the following three parts: The first part asked for employees' basic information, including demographic variables (age, gender, marital status, educational level, etc.) and organizational/working variables (job position, number of years working, salary level, etc.). The career anchor scale developed by Schein (1978) was used in the second part, which was substantiated by extensive empirical studies and was more representative [7]. The career anchor scale had 40 items in all, with every anchor including five items, for example, 'I feel a sense of achievement when I am integrating and managing others' work' and 'I hope I can reconcile the demands of my job and my family'. The job characteristic scale was developed by the present research team and had 37 items in all (Table A1). Among these, the managerial characteristic, challenge characteristic, and service and dedication characteristic had four items each, whereas other characteristics including the technological characteristic, autonomous characteristic, secure and stable characteristic, entrepreneurial creative characteristic and job and family balance characteristic had five items each. For example, 'my job is characterized by supervising, influencing, leading, and controlling others' and 'I always feel restless and nervous because of poor job stability'. To avoid respondents choosing neutral answers, Likert 6 rating scales were used [34], and all items were evaluated by self-reporting, with 1 indicating 'completely inconsistent', 2 indicating 'reasonably inconsistent', 3 indicating 'partly inconsistent', 4 indicating 'partly consistent', 5 indicating 'reasonably consistent', and 6 indicating 'completely consistent'. Reversed items were transformed to positive rating values with the high value representing high significance.

For compactness, the eight career anchors and the job characteristics were abbreviated to the following forms: technological competence anchor (TA), technological characteristic (TC); managerial competence anchor (MA), managerial characteristic (MC); autonomy and independence anchor (AA), autonomous characteristic (AC); security and stability anchor (SSA), secure and stable characteristic (SSC); entrepreneurial creativity anchor 
(ECA), entrepreneurial creative characteristic (ECC); service and dedication anchor (SDA), service and dedication characteristic (SDC); challenge anchor (CA), challenge characteristic (CC); lifestyle anchor (LA); and job and family balance characteristic (JFBC).

\subsection{Sample and Data}

To ensure the reliability and validity of the questionnaire, a preliminary investigation and a formal investigation were conducted successively. In February 2018, a preliminary investigation was conducted in Jiangsu Province, and the data was collected among working adults by combining online questionnaires and paper questionnaires, which was a way to obtain a wider range of samples that can avoid sample selection bias to a certain extent. A total of 244 questionnaires were collected through targeted surveys, of which 203 were acceptable, giving an effective rate of $83 \%$. In addition, item analysis, reliability, and validity analyses were performed to adjust and eliminate inferior items, leading to the development and formalization of the formal questionnaire.

In March 2018, the formal investigation was conducted in East China and Pearl River Delta, and the data was mainly collected by questionnaire survey. In the process of investigation, we explained to the respondents that the results were only used for scientific research, and their personal information would be kept private. We also highlighted that their careful and honest answers would significantly contribute to our research. Four hundred and thirty-two samples were collected in the formal investigation; after deleting invalid questionnaires such as too many blanks, 407 effective samples remained, giving an effective rate of $94.21 \%$. In the formal samples, 194 were males, accounting for $47.7 \%$ of the total sample, and 213 were females, accounting for $52.3 \%$. The proportion of employees between 20 and 29 years old was $62.9 \%$, followed by employees between 40 to 49 years old, accounting for $23.2 \%$; employees more than 50 years old represented the smallest proportion. The proportions of employees with high school education, junior college, and undergraduate education were $4.7 \%, 14.5 \%$ and $50 \%$ respectively. The proportion of married employees was $51.4 \%$, followed by single employees at $26.5 \%$. In addition, various industries including the mining industry, education, service industry and other industries were included to ensure the representativeness of the sample. SPSS 17.0 and Amos 7.0 were used to perform the data analyses and tests in this study.

\subsection{Reliabilityand Validity Analysis}

Before the specific analysis, the reliability and validity of the relevant scales were tested. Cronbach's a coefficient was used to measure the reliability of the questionnaire in this study. The results showed that the Cronbach's values for the career anchor and job characteristic scales were 0.897 and 0.870 , respectively, which were larger than 0.7 . The corresponding Cronbach's values of latent variables were between 0.694-0.876, which were larger than 0.6. These indicated that the overall scale had good reliability, and that the scale had passed the reliability test [35]; based on a large number of literature studies, this study strictly followed the scale development procedure and consulted 5 experts in the management field to discuss and revise it, so the scales had good content validity.

In addition, the structural equation model was used by AMOS 7.0 to carry out confirmatory factor analysis and to test the validity of the structures of the two scales. The results (Table 1) showed that the goodness-of-fit test parameters $(\mathrm{X} 2 / \mathrm{df}=2.564, \mathrm{RMSEA}=0.023$, $\mathrm{NFI}=0.822, \mathrm{RFI}=0.823, \mathrm{CFI}=0.892)$ of the career anchor eight-factor model had reached the acceptable range, and the goodness-of-fit values $(\mathrm{X} 2 / \mathrm{df}=3.920, \mathrm{RMSEA}=0.023$, $\mathrm{NFI}=0.879, \mathrm{RFI}=0.814, \mathrm{CFI}=0.830$ ) of the eight-factor model of job characteristics had also reached the acceptable range-so both scales had good structural validity. Besides this, the standardized load values of each latent variable item were larger than 0.75 and the average extraction variation (AVE) of each factor was larger than 0.5 , which indicated that convergence validity was good [36]. Thus, the scales passed the validity test. 
Table 1. Results of confirmatory factor analysis.

\begin{tabular}{cccccc}
\hline & X2/df & RMESA & NFI & RFI & CFI \\
\hline Career anchor & 2.564 & 0.023 & 0.822 & 0.823 & 0.892 \\
\hline Job characteristic & 3.920 & 0.023 & 0.879 & 0.814 & 0.830 \\
\hline
\end{tabular}

\section{Results and Discussion}

\subsection{Descriptive Statistics for Career Anchors and Job Characteristics}

To clarify the current situation of career choice and real career demand, this research firstly conducted a statistical analysis on the distribution of job characteristics and career anchors; the results are shown in Figure 2.

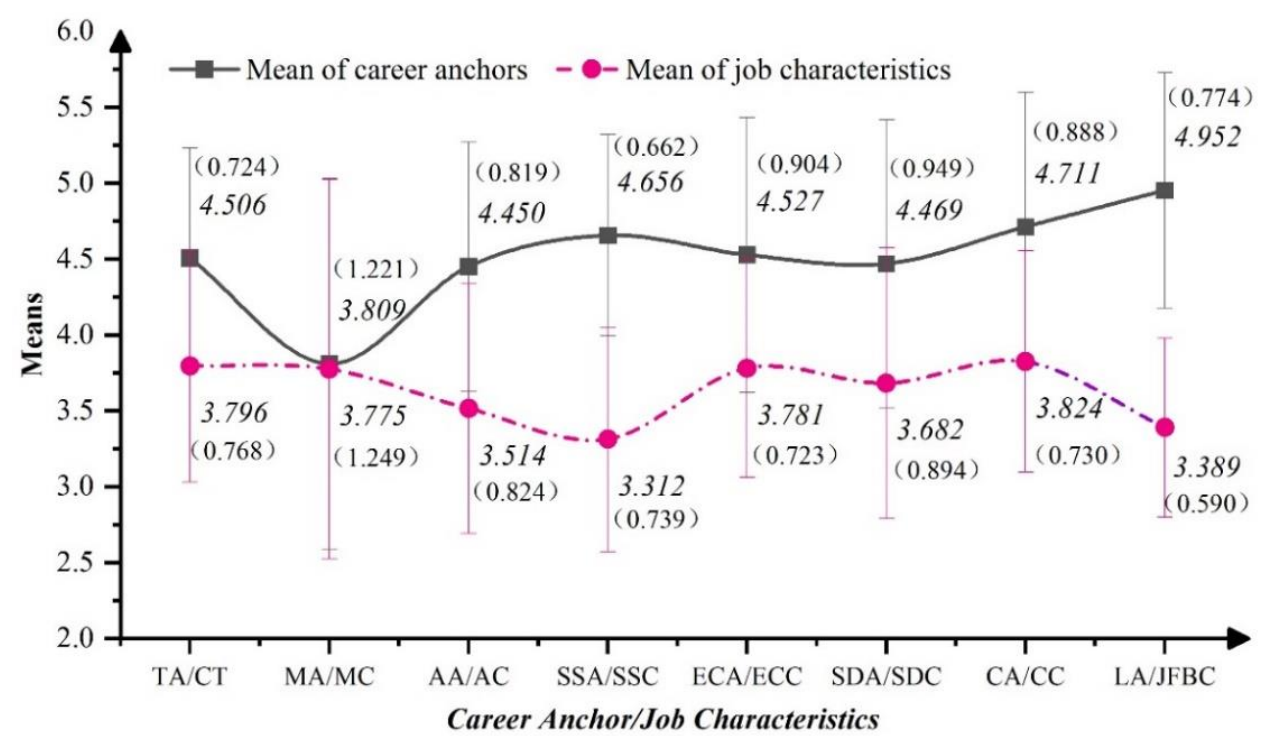

Figure 2. Means (standard deviation) of career anchor and job characteristics.

Figure 2 shows the mean distributions of career anchors and job characteristics. The black square symbols in the figure indicate the distribution of career anchors, the pink circle symbols indicate the distribution of job characteristics, and the values in parentheses are the standard deviation of each variable. As shown in Figure 2, among the eight career aspirations (career anchors), life anchors had the highest mean value (4.952) and management anchors had the lowest mean value (3.809), and among the eight job choices (job characteristics), employees had the highest perception of challenge characteristics (3.824) and lowest perception of security and stability characteristics (3.312). The relatively high mean values of life anchors and the relatively low mean values of work-family balance characteristics corresponding to life anchors reflected that most employees in the study sample had relatively large life-oriented job aspirations, but these employees had relatively low perceptions of work-family balance job characteristics, which indicated that employees' aspirations were not aligned with their career choices. A similar situation existed in other career anchor areas, which indicated that employees' career aspirations were not aligned with their career choices. Overall, from the trend of the lines in the above graph, the mean value of career anchors was significantly higher than employees' perceived job characteristics, which indicated that employees' career aspirations and realistic career choices were deviating to some extent.

To further clarify the characteristics of the distribution of career aspirations (career anchors) in the study sample, this study used a mean significance test to determine the types of career anchors of the subjects. The findings of the mean value test of 407 samples indicated that career anchors might be represented by three properties: single career anchor, multiple career anchors, and vague career anchor. In our study, one's career anchor was defined as a single career anchor if its mean value was the highest and was significantly 
different from that of other career anchors. In addition, multiple career anchors referred to the condition that one individual's two or three career anchors had the same mean values, with no significant difference among them. The last type was a vague career anchor, which was defined as there being no significant differences among the eight career anchors, or that more than three career anchors had the same mean value. A total of 292 samples belonged to the single career anchor group, accounting for $71.74 \%$, followed by multiple career anchors (106 samples, accounting for 26.04\%) and by only 9 samples with vague career anchors, accounting for $2.21 \%$. We also conducted a statistical analysis of individuals with single career anchors and multiple career anchors; the results are shown in Figure 3.
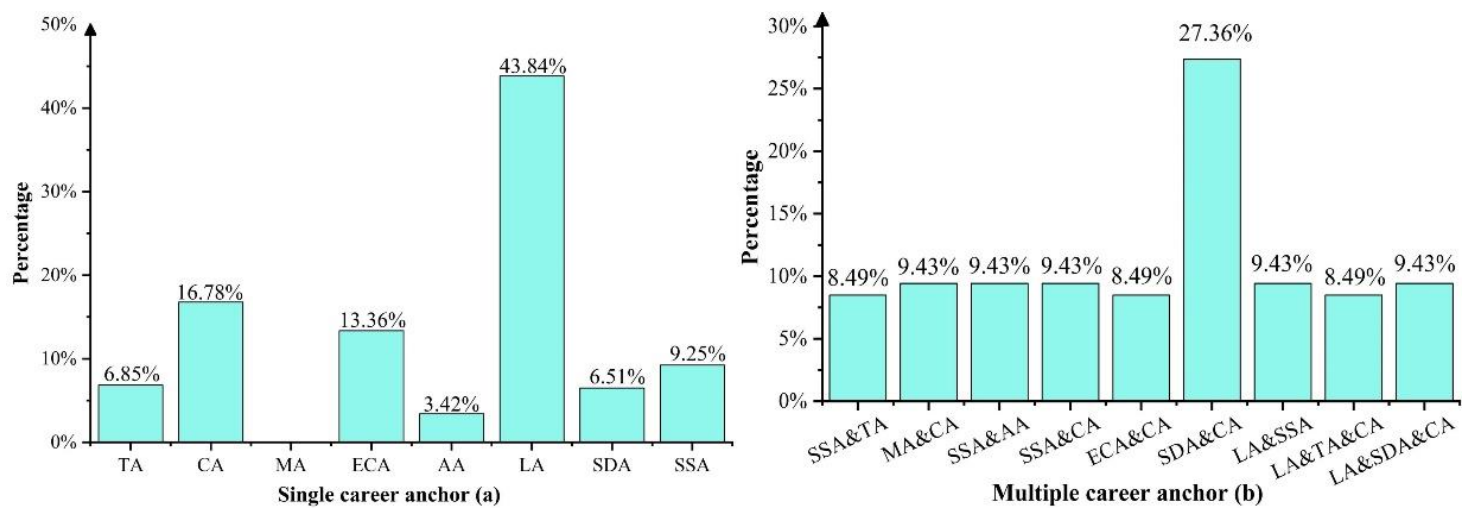

Figure 3. Distributions of single career anchor and multiple career anchor.

Figure 3 showed the distribution of single career anchors and multiple career anchors. As can be seen from Figure 3, among the single career anchor types, the life anchor had the largest proportion, which indicated that most employees had relatively higher demands for life type jobs, which may be related to the higher overall work pressure at this stage; the higher work pressure made employees more inclined to pursue life balance-type jobs. In addition, the study did not find any individuals with a single management anchor, which may be due to the fact that most employees were sensitive to managerial job demands, causing the respondents to avoid answering the questions deliberately. Meanwhile, among the individuals with multiple career anchors, most of them had both challenge anchors and service anchors, and challenge anchors were the most common anchor type among individuals with multiple career anchors. This indicated that most employees still want their jobs to be challenging and service-oriented, which is consistent with the findings of Chachadi et al. (2012) that service anchors are the more prevalent anchor type [37].

\subsection{Difference Analysis of Career Anchors}

One-way ANOVA in SPSS 17.0 was used to analyze the significance and differences of the eight career anchors on demographic and organizational/working variables; detailed results are shown in Table 2.

Table 3 showed the statistical results of the variance of career demands (career anchors) on demographic variables and organizational/job variables. As can be seen from Table 2, most of the career anchors differed significantly on demographic variables and organizational/job variables, with no differences in job rank for security and stability anchors and only significant differences in gender for technical anchors and security and stability anchors. At the gender level, only the technical competence anchor and security and stability anchor had significant differences by gender; male employees had higher scores in technical competence, whereas females had a preference for security and stability. At the age level, there were significant differences in the eight types of career anchors by age. Specifically, employees aged 50 and above had the highest scores on technical anchors, managerial anchors, autonomous and independent anchors, and challenge anchors, while employees aged 30-39 had the highest scores on security and stability anchors, creative and entrepreneurial anchors, service anchors, and life anchors; the rest of the age groups did 
not have significant differences in their scores on the various anchor types. At the marital status level, the married group scored highest on the technology anchor, management anchor, security and stability anchor, creation and entrepreneurship anchor, service anchor and challenge anchor; single employees score highest on the autonomy and independence anchor. At the education level, there were significant differences in the eight categories of career anchors in terms of education level. Among them, employees with college degrees had the highest scores on the technology anchor, management anchor, security and stability anchor, creativity and entrepreneurship anchor, service anchor, and challenge anchor, while employees with bachelor's degrees had the highest scores on the autonomy and independence anchor and lifestyle anchor. At the job position level, senior leaders gave the highest score for the technical competence anchor, middle-level leaders had the highest scores in the managerial competence anchor, autonomy and independence anchor, and lifestyle anchor, low-level leaders gave the highest score to entrepreneurial creativity, and ordinary staff gave the highest score to challenge. At the years of education level, there were significant differences in the eight types of career anchors. Specifically, employees with more than 20 working years gave the highest score to the technical competence anchor, those with 11 to 20 years gave the highest score to the managerial competence anchor, those with 6 to 10 years had the highest scores in the autonomy and independence anchor, security and stability anchor, entrepreneurial creativity anchor, service and dedication anchor, and challenge anchor, and those with 2 to 5 years paid more attention to the lifestyle anchor. At the salary level, there were significant differences in the eight types of career anchors. Specifically, employees with salaries between 15,000 and 29,999 yuan gave the highest scores to the technical competence anchor, autonomy and independence anchor, challenge, and lifestyle anchor. Those making 3000 to 4999 yuan gave the highest score to the security and stability anchor, whereas employees making less than 3000 yuan gave the highest scores to the managerial competence anchor, entrepreneurial creativity anchor, and service and dedication anchor.

Table 2. Differences of career anchors in statistic variables.

\begin{tabular}{|c|c|c|c|c|c|c|c|c|}
\hline Variable & TA & MA & AA & SSA & ECA & SDA & CA & LA \\
\hline \multirow{2}{*}{ Gender } & Sig *** & \multirow{2}{*}{ NS } & \multirow{2}{*}{ NS } & Sig *** & \multirow{2}{*}{ NS } & \multirow{2}{*}{ NS } & \multirow{2}{*}{ NS } & \multirow{2}{*}{ NS } \\
\hline & male ${ }^{(h)}$ & & & Female $^{(h)}$ & & & & \\
\hline \multirow{2}{*}{ Age } & Sig *** & Sig *** & Sig *** & Sig *** & Sig *** & Sig *** & Sig *** & Sig * \\
\hline & Above $50^{(\mathrm{h})}$ & Above $50^{(\mathrm{h})}$ & Above $50^{(\mathrm{h})}$ & 30 to $39^{(h)}$ & 30 to $39^{(h)}$ & 30 to $39^{(h)}$ & Above $50^{(\mathrm{h})}$ & 30 to $39^{(h)}$ \\
\hline \multirow{2}{*}{ Marital status } & Sig *** & Sig *** & Sig *** & Sig *** & Sig *** & Sig *** & Sig *** & Sig * \\
\hline & Married $^{(h)}$ & Married $^{(h)}$ & Single ${ }^{(h)}$ & Married $^{(\mathrm{h})}$ & Married $^{(\mathrm{h})}$ & Married $^{(h)}$ & Married $^{(\mathrm{h})}$ & In-love ${ }^{(h)}$ \\
\hline \multirow[b]{2}{*}{ Educational level } & Sig *** & Sig *** & Sig ** & Sig *** & Sig *** & Sig *** & Sig *** & Sig *** \\
\hline & $\begin{array}{l}\text { Junior } \\
\text { college }^{(h)}\end{array}$ & $\begin{array}{l}\text { Junior } \\
\text { college }^{(h)}\end{array}$ & $\begin{array}{c}\text { Under- } \\
\text { graduate }^{(h)}\end{array}$ & $\begin{array}{l}\text { Junior } \\
\text { college }^{(h)}\end{array}$ & $\begin{array}{c}\text { Junior } \\
\text { college }^{(h)}\end{array}$ & $\begin{array}{l}\text { Junior } \\
\text { college }^{(h)}\end{array}$ & $\begin{array}{l}\text { Junior } \\
\text { college }^{(h)}\end{array}$ & $\begin{array}{c}\text { Under- } \\
\text { graduate }^{(h)}\end{array}$ \\
\hline \multirow[b]{2}{*}{ Job position } & Sig *** & Sig * & Sig *** & \multirow[b]{2}{*}{ NS } & Sig *** & \multirow[b]{2}{*}{ NS } & Sig *** & Sig *** \\
\hline & $\begin{array}{c}\text { Senior } \\
\text { leaders }\end{array}$ & $\begin{array}{l}\text { Middle-level } \\
\text { leaders }^{(\mathrm{h})}\end{array}$ & $\begin{array}{l}\text { Middle-level } \\
\text { leaders }\end{array}$ & & $\begin{array}{l}\text { Low-level } \\
\text { leaders }\end{array}$ & & $\begin{array}{l}\text { Ordinary } \\
\text { staff }^{(h)}\end{array}$ & $\begin{array}{l}\text { Middle-level } \\
\text { leaders }^{(h)}\end{array}$ \\
\hline \multirow{2}{*}{$\begin{array}{c}\text { Number of years } \\
\text { working }\end{array}$} & Sig *** & Sig *** & Sig *** & Sig *** & Sig *** & Sig *** & Sig *** & Sig ** \\
\hline & Above $20^{(\mathrm{h})}$ & 11 to $20^{(\mathrm{h})}$ & 6 to $10^{(h)}$ & 6 to $10^{(\mathrm{h})}$ & 6 to $10^{(h)}$ & 6 to $10^{(h)}$ & 6 to $10^{(h)}$ & 2 to $5^{(h)}$ \\
\hline \multirow[b]{2}{*}{ Salary level } & Sig *** & Sig *** & Sig *** & Sig *** & Sig *** & Sig *** & Sig *** & Sig *** \\
\hline & $\begin{array}{l}15,000 \text { to } \\
29,999^{(h)}\end{array}$ & $3000^{(h)}$ & $\begin{array}{l}15,000 \text { to } \\
29,999^{(h)}\end{array}$ & $\begin{array}{l}3000 \text { to } \\
4999^{(h)}\end{array}$ & $3000^{(h)}$ & $3000^{(h)}$ & $\begin{array}{l}15,000 \text { to } \\
29,999^{(h)}\end{array}$ & $\begin{array}{l}15,000 \text { to } \\
29,999^{(h)}\end{array}$ \\
\hline
\end{tabular}

*** Significant ( $\mathrm{p}=001$ level two-tailed); ${ }^{* *}$ Significant $\left(p=0.01\right.$ level two-tailed); ${ }^{*}$ Significant $(p=0.05$ level two-tailed). NS $=$ not significant. $X^{(h)}$ indicates a higher score for $\mathrm{X}$ group, e.g., male; ${ }^{(\mathrm{h})}$ indicates a higher score for the male group; junior college is a unique type of institution in China, which is mainly for high school graduates with low grades, equivalent to community colleges in the United States. 
Table 3. Degree of fit of seven single career anchors.

\begin{tabular}{cccccc}
\hline Type & \multicolumn{2}{c}{ Job Fit Characteristic } & Degree of Fit & Serious Deviation Rate \\
\hline TA & TC & SSC & CC & $40.91 \%$ & $31.82 \%$ \\
\hline AA & AC & ECC & JFBC & $27.27 \%$ & $54.55 \%$ \\
\hline SSA & SSC & TC & SDC & $31.25 \%$ & $43.75 \%$ \\
\hline ECA & ECC & AC & MC & $62.79 \%$ & $18.60 \%$ \\
\hline SDA & SDC & SSC & JFBC & $43.48 \%$ & $43.48 \%$ \\
\hline CA & CC & TC & MC & $38.33 \%$ & $38.33 \%$ \\
\hline LA & JFBC & AC & SDC & $21.28 \%$ & $62.77 \%$ \\
\hline
\end{tabular}

Note: The formula for matching rate between career anchors and job characteristics is: the number of matching job characteristics/total number of job characteristics* $100 \%$; the formula for serious deviation rate between career anchors and job characteristics is: the number of deviating job characteristics/total number of job characteristics* $100 \%$.

At the gender level, female employees gave high scores to the security and stability anchor, indicating their high preference for stable work and safety. This may be due to the fact that women tend to choose positions that are less stressful, less challenging, and more comfortable in terms of career choice [38], and these attributes may lead women to prefer finding a secure job. At the age level, employees more than 50 years old gave the highest scores to the technical competence anchor, managerial competence anchor, autonomy and independence anchor, and challenge anchor, whereas employees from 30 to 39 years old gave the highest scores to the security and stability anchor, entrepreneurial creativity anchor, service and dedication anchor, and lifestyle anchor. This was interpreted to mean that older employees had rich working experience and a higher inclination to pursue individual occupational development. Besides, with the development of scientific technology and the improvement of living standards, a job has become more than a way of earning a living, and employees from 30 to 39 had more demands beyond basic survival needs-which to a certain extent is consistent with Maslow's hierarchy of needs theory. At the marital status level, married employees had higher scores on most career anchors and were under high pressure from both their work and their life. These pursuits of the value of their work reflect their sense of obligation and responsibility to their families. At the education level, employees with junior college degrees had higher scores on most career anchors, reflecting that they had a clear perception of their career aspirations. We believe that this was closely related to their training model, where the combination of theoretical teaching and work practice enables these students to consolidate and improve their professional skills early on and have a clearer understanding of their career anchors. At the job position level, previous studies have suggested that people in leadership positions tend to have management anchors [39], whereas in this study, only middle-level leaders had more significant management anchor characteristics. This may be due to the fact that mid-level leaders have a clearer perception of their management talents and are more inclined to pursue jobs with management characteristics. It is worth noting that because career anchors are formed on the basis of certain work experience, individuals' career anchors will gradually stabilize with years of work experience. With the accumulation of experience, individuals have more comprehensive cognition of different occupations, and their professional aspirations will become clearer. In addition, with the development and popularization of modern information technology, work styles are more diverse and flexible, and the post-80s and post-90s are gradually becoming the main force in the workplace; they have a different understanding of work and life, and these changes may also prompt employees to have new demands on their jobs. 


\subsection{Fit between Career Anchors and Job Characteristics}

\subsubsection{Matching Rate Analysis}

To further explore the match or deviation between individual career statements and career choices, this study constructed a match rate formula and a deviation rate formula based on the octagonal theory of career anchors and made specific measurements of the match between career anchors and job characteristics. The octagonal correlation theory of career anchors suggests that each career anchor has its own corresponding job characteristics, that is, the highest correlation between adjacent job characteristics-while the job characteristics on the diagonal are the least compatible and often mutually exclusive [40]. In this study, the identification and measurement of matching career anchors with job characteristics were also based on the octagonal theory of career anchors and combined with the rules of "optimal matching" and "suboptimal matching". For example, the job characteristics matching with the challenge anchor are challenge characteristics, technical characteristics and management characteristics, among which the challenge characteristics are the optimal match and the remaining two characteristics are the suboptimal matches. During this specific study, it was found that some of the samples had multiple career anchors that were exclusive of each other. This made it difficult to establish an accurate standard to measure the fit between specific career anchors and job characteristics. Therefore, single career anchors were chosen for further analysis, including the degree of fit and rate of serious deviation between career anchors and job characteristics. For instance, a high deviation rate indicated a high proportion of job characteristics involving diagonally opposite career anchors and their adjacent career anchors across all job characteristics. The results are shown in Table 3.

Table 3 shows the matching results between the seven types of single career anchors and job characteristics. As can be seen from Table 3, the entrepreneurial creativity anchor showed the highest degree of fit $(62.79 \%)$ with its job characteristics, which indicates that entrepreneurial creativity anchor individuals tended to choose jobs with innovative and creative characteristics when choosing their careers. The entrepreneurial creativity anchor individuals tended to assert themselves, preferred creative work environments, and were able to face and deal with some practical problems well [41]. These factors made entrepreneurial creativity anchor individuals stick to their original intention when facing career choices, and thus, entrepreneurial creativity anchor individuals had more potential to work in jobs that matched their original intention, and their job matching rates were relatively high. This also provides a corresponding explanation for the high matching rate between individuals with creative entrepreneurial anchors and job characteristics in the study.

Except for the entrepreneurial creativity anchors, all anchor types showed low matching rates, suggesting that inconsistency between career aspirations and career choices (i.e., career choice divergence) has become a common phenomenon. Among them, employees with lifestyle anchors had the most serious deviation from their current job characteristics, with a match rate of only $21.28 \%$ and a serious deviation rate of $62.77 \%$. In this study, employees with lifestyle anchors made up the largest proportion of the total sample, yet they mostly chose to work in jobs with technical, challenging and managerial characteristics, which to some extent reflects the real situation of employees in the current workplace. This may be due to the fact that as workplace competition becomes more and more intense, employees present frequent conflicts between work and life, which leads to frequent phenomena such as burnout and low job satisfaction [42,43]. Employees with lifestyle anchors are prone to encounter choice dilemmas in these conflicts and have difficulty in getting out of the fierce competition for work and may choose sub-optimal matches in order to make a living - thus having a lower match rate. In general, due to the fierce competition in all organizations and departments, the match between the career demands of groups with six types of career anchors, including technical anchors, independent anchors, security and stability anchors, service anchors, challenge anchors, and life anchors, and their real career choices is alarming-management must pay attention 
to these individuals and give special guidance to reduce the incidence of job burnout and stabilize organizational performance.

\title{
4.3.2. Career Preference Analysis
}

According to the career anchor octagon theory, every single career anchor had three job characteristics that fitted it well. One can maximize one's own occupational value by taking on a job that fits well. A remarkable observation was that different career anchors had different preferences for job characteristics that fit. To clarify the highest preference among job characteristics that fit, the mean value was computed for the same data group in the same career anchor. After processing these values, we drew a line chart of the career preferences of seven types of single career anchor groups; the results are shown in Figure 4.
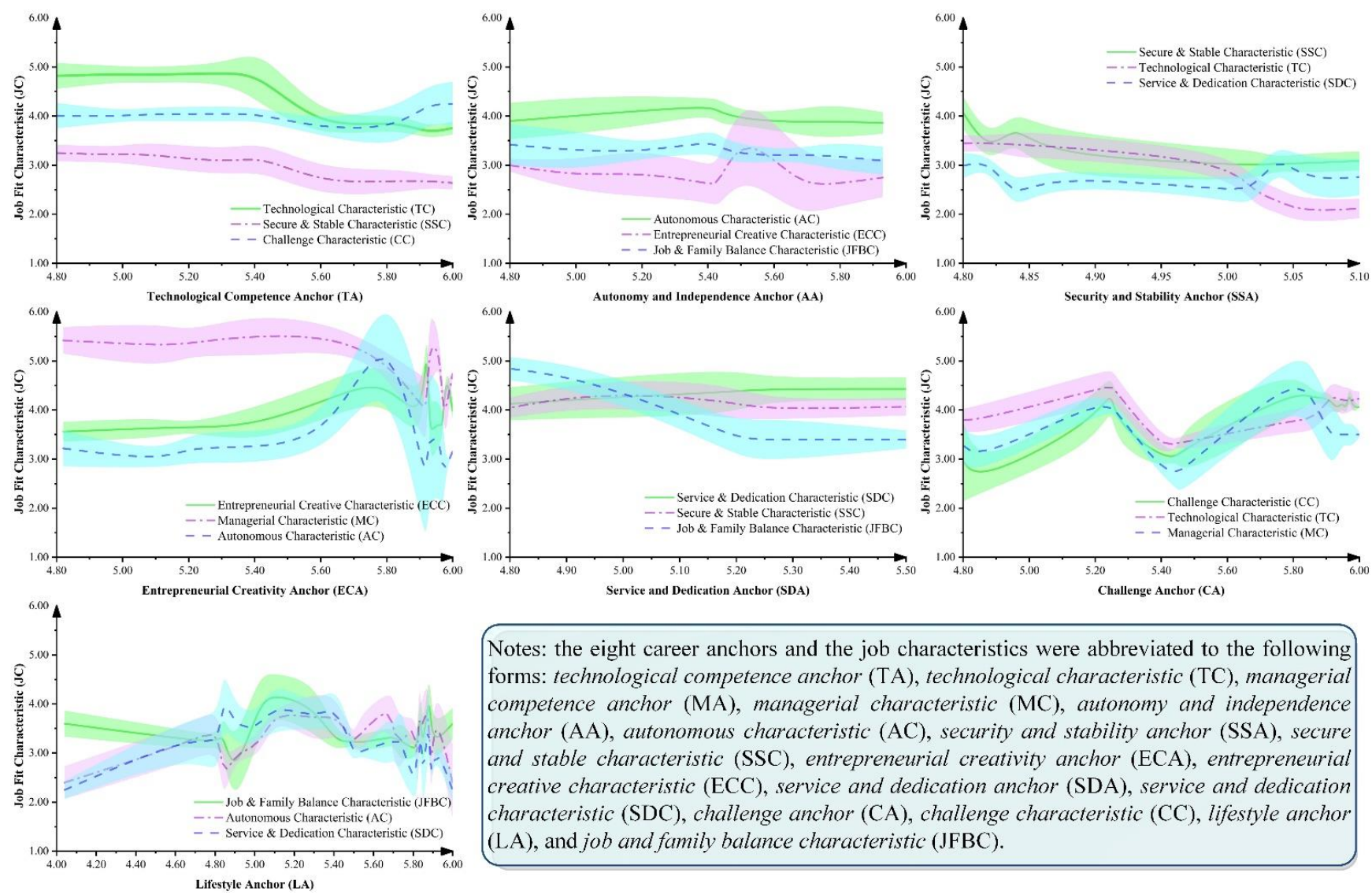

\begin{abstract}
Notes: the eight career anchors and the job characteristics were abbreviated to the following forms: technological competence anchor (TA), technological characteristic (TC), managerial competence anchor (MA), managerial characteristic (MC), autonomy and independence anchor (AA), autonomous characteristic (AC), security and stability anchor (SSA), secure and stable characteristic (SSC), entrepreneurial creativity anchor (ECA), entrepreneurial creative characteristic (ECC), service and dedication anchor (SDA), service and dedication characteristic (SDC), challenge anchor (CA), challenge characteristic (CC), lifestyle anchor (LA), and job and family balance characteristic (JFBC).
\end{abstract}

Figure 4. Comparison of career choice preferences.

Figure 4 shows the career preferences of the seven types of single career anchor groups. As can be seen from Figure 4, the seven anchor types showed significant differences in their preferences for the selection of matching job characteristics. The results of Figure 4 have been summarized in Table 4 to represent the preferences clearly.

As shown in Table 4, the technical competence anchor, autonomy and independence anchor, security and stability anchor, service and dedication anchor, and lifestyle anchor were the most preferred job characteristics taken by themselves, whereas the entrepreneurial creativity anchor had the highest preference for managerial characteristics and the challenge anchor showed a higher occupational expectation for technical characteristics. Combining the octagonal model of career anchors with the other five anchor types, the results showed that, with the center of the octagonal model of career anchors as the observation perspective, the preference of specific career anchors for job characteristics on the right side was always greater than that for job characteristics on the left side. Generally speaking, specific career anchors have the highest selection of job characteristics 
corresponding to themselves, but both entrepreneurial creativity anchors and challenge anchors show a "suboptimal match", and the selection of suboptimal job characteristics by specific career anchors also differs. Overall, the research results related to the career preferences of these specific career anchors can provide some reference for corporate career development management.

Table 4. Comparison of career choice preferences.

\begin{tabular}{cc}
\hline Types & Occupational Preference \\
\hline Technical competence & TC $>$ CC $>$ SSC \\
\hline Autonomy and independence & AC $>$ JFBC $>$ ECC \\
\hline Security and stability & SSC $>$ TC $>$ SDC \\
\hline Entrepreneurial creativity & $\mathrm{MC}>$ ECC $>$ AC \\
\hline Service and dedication & SDC $>$ SSC $>$ JFBC \\
\hline Challenge & TC $>$ MC $>$ CC \\
\hline Lifestyle & JFBC $>$ SDC $>$ AC
\end{tabular}

\subsection{Limitations}

This study also has some limitations and needs to be further improved: (1) In terms of research samples, due to the limitations of survey conditions and time, the data was collected among working adults by combining online questionnaires and paper questionnaires. Although this could represent the career development of employees to a certain extent and meet the basic requirements of the statistical research method for samples, there were still some deficiencies in the number and regional distribution of the survey samples, so the research results could not cover all situations. In future studies, we can further cooperate with the Ministry of Labor to expand the scope and number of samples, conduct sample surveys for different groups, and improve the universality and representativeness of samples, so as to better explore the rules and improve the research value. (2) In terms of data survey, since self-reported questionnaires were used in data collection, some deviations in expression and personal understanding would inevitably occur, thus affecting the accuracy of research results to a certain extent. At the same time, the questionnaires involved the sensitive topic of potential occupational orientation in the workplace, which might lead to respondents' hesitation in answering and thus affect the quality of data. (3) In terms of research methods, there are many methods to conduct systematic research on employees' career appeals and career choices. This study only used statistical analysis, difference analysis, and other methods to analyze the retrieved literature. In future, metaanalysis, bibliometric analysis, path analysis, and other analysis methods can be used to study the career choices of employees.

\section{Conclusions}

Career choice is an important behavior for people wanting to develop their social life and is a key link to doing so. The matching of career choice with an individual's real work demands will have a significant impact on the development of individuals, organizations, and society. From the perspective of the matching of career anchors and job characteristics, this study explored the distribution and difference characteristics of employees' career demands and their career choices through a survey of 407 employees, and further discussed the matching status of this. Related research results show important theoretical innovations and practical significance in guiding individuals to make scientific career choices and assisting managers in recruitment and selection.

(1) The results of the descriptive statistical analysis showed that individual career demands (career anchors) presented three attributes: single, multiple, and unclear. Among the single career anchor types, life anchors had the largest proportion, while 
among multiple career anchor individuals, individuals with both challenge anchors and service anchors accounted for the majority.

(2) The analysis results of the different characteristics showed that individual career demands (career anchors) were significantly different across most demographic variables and organizational/work variables. Specifically, the eight types of anchors had significant differences in age, marital status, education level, working years and wage levels.

(3) The matching feature analysis results showed that the deviation between employees' career demands and their career choices seemed to be a common phenomenon, with the highest degree of fit $(62.79 \%)$ with the entrepreneurial creativity anchor and the lowest degree of fit $(21.28 \%)$ with the lifestyle anchor. In addition, in an analysis of three job fit characteristics, the entrepreneurial creativity anchor had a significant preference for managerial characteristics, whereas the challenge anchor had a significant preference for technological characteristics. The degrees of fit of the other anchors were characterized by the frequency of 'right suboptimal fit' being larger than that of 'left suboptimal fit'. In other words, a specific career anchor had a significant preference for job characteristics matched by the right career anchor, with the midpoint of the career anchor octagon model defining the angle of observation.

\section{Suggestions}

Career choice is an important behavior for people wanting to develop their social life and is a key link to doing so. Their matching with the individual's real career demands will have an important impact on the development of individuals, organizations, and society. Based on the above analysis of matching status between career anchor and job characteristics, this study put forward the following suggestions.

(1) Pay attention to early career planning. This study found that individual career demands (career anchors) presented three attributes of single, multiple, and unclear-indicating that some employees did not have clear career demands. Based on this, we suggest attaching importance to early career planning and establishing scientific career demands. Specifically, a career planning steering committee can be established to systematically help individuals to carry out early career planning and enhance their cognition of their own career anchors. Early career planning education can be carried out to promote individual identification or to explore their own career demands. Vocational communication activities can be actively carried out to help individuals understand the characteristics and skills of various occupations.

(2) Carry out recruitment and selection management based on professional anchors. This study found that the deviation between individual career demands and career choices was common, which indicated that many employees' own career demands were not consistent with the real job characteristics, which may reduce individual job satisfaction and organizational performance. Based on this, we suggest that managers carry out recruitment and selection management based on career anchors. Specifically, regular career anchor tests can be carried out to recruit employees with relevant characteristics and specific career demands. Abundant vocational training activities can be carried out to encourage employees to continuously recognize their own career anchors and consciously choose jobs that match their own career anchors.

(3) Carry out career development management based on career preference. This study found that individuals with different career demands (career anchors) showed significant differences in their preference for matching job characteristics. For example, entrepreneurial anchors had the highest preference for managerial jobs, while challenge anchors had higher career expectations for technical jobs. Based on this, we suggest that managers carry out career development path planning based on career preference. Specifically, a variety of career development paths can be designed scientifically to provide different development paths for individuals with different career anchors. For example, individuals with serious deviations can adjust their work posi- 
tions to reduce conflicts. A variety of work incentives can be designed scientifically to provide different career incentives for individuals with different career anchors. For example, for innovative employees, the focus of incentives should be on constantly giving new challenges and strengthening the public recognition of work. Different work environments can be created for individuals with different career anchors; for example, for those with business anchors and life anchors, a more relaxed working atmosphere should be given to those with business anchors, and their innovation should be encouraged to create greater benefits for the organization, while more humanistic care should be given to those with life anchors.

Author Contributions: Conceptualization, H.C.; Data curation, H.C., Y.W.; Formal analysis, Y.W.; Funding acquisition, H.C.; Investigation, Y.W., Y.D.; Methodology, Y.W.; Project administration, H.C., Y.W.; Resources, Y.W., Y.D.; Software, Y.W.; Supervision, H.C.; Validation, H.C.; Visualization, Y.W.; Roles/Writing—original draft, Y.W., Y.D.; Writing—review and editing, H.C., Y.W. All authors have read and agreed to the published version of the manuscript.

Funding: This work was supported by the the Jiangsu Philosophy and Social Sciences Excellent Innovation Cultivation Team (Grant No: 2017ZSTD031).

Institutional Review Board Statement: Not applicable.

Informed Consent Statement: Informed consent was obtained from all individual participants included in the study.

Data Availability Statement: The datasets generated and/or analyzed during the current study are available from the corresponding author upon reasonable request.

Conflicts of Interest: The authors declare that they have no competing interests.

\section{Appendix A}

Table A1. The job characteristic scale.

\begin{tabular}{|c|c|}
\hline 1 & My job requires high technical skills \\
\hline 2 & My job has a high professional background requirement for people who engage in it \\
\hline 3 & The job I am engaged in has high requirements for professional qualifications and technical levels \\
\hline 4 & Without solid professional knowledge, I can't carry out my current job well \\
\hline 5 & The jobs I do don't need to have a lot of expertise \\
\hline 6 & Most of my work is related to managing people, managing directors and coordinating various resources in the organization \\
\hline 7 & My work requires supervision, influence, leadership, and control of other personnel in the organization \\
\hline 8 & My work often requires a lot of policies or decisions \\
\hline 9 & My work has nothing to do with managing directors and others \\
\hline 10 & I work with a strong independence \\
\hline 11 & My job gives me a great opportunity to independently and freely decide how to complete the task \\
\hline 12 & My job gives me a lot of space to play so that I can do it according to my own thinking \\
\hline 13 & There is no room for me to play independently in my work \\
\hline 14 & My job does not give me any opportunity to personally initiate or decide on the work to do \\
\hline 15 & My job requires me to innovate regularly \\
\hline 16 & My job is very demanding of creativity and innovation \\
\hline 17 & My job content is full of innovation \\
\hline 18 & My job doesn't require me to innovate regularly \\
\hline 19 & My job is step by step and very programmed \\
\hline 20 & My job is very challenging \\
\hline
\end{tabular}


Table A1. Cont.

\begin{tabular}{ll}
\hline 21 & My job is very difficult and needs to regularly deal with changes and challenges \\
\hline 22 & My job requires challenging myself regularly \\
\hline 23 & My job is relatively simple and not challenging \\
\hline 24 & My job is very stable, and I never worry about any variables in my work \\
\hline 25 & My job makes it unnecessary for me to worry and be anxious about the future \\
\hline 26 & My job gives me a very safe feeling \\
\hline 28 & My job gives me a very stable income and security \\
\hline 29 & Most of my job is to provide help or service to a person or organization \\
\hline 30 & The biggest feature of my work is to provide help or service to a person or organization \\
\hline 31 & Whether the service provided is good and whether the service object is satisfied is very important to my job \\
\hline 32 & My job does not require me to serve or help to someone else or an organization \\
\hline 33 & My job will not conflict with my personal or family life \\
\hline 34 & My job gives me a lot of opportunities to enjoy personal time and family life \\
\hline 35 & I have a good balance between personal time and work at work \\
\hline 36 & My job makes it difficult for me to balance private time with work \\
\hline 37 & My job makes it difficult for me to balance work with family conflicts \\
\hline
\end{tabular}

\section{References}

1. Dierendonck, D.V. The influence of planning, support and self-concordance on goal progress and job satisfaction. Evid. Based HRM 2015, 3, 206-221. [CrossRef]

2. Lent, R.W.; Brown, S.D. Career decision making, fast and slow: Toward an integrative model of intervention for sustainable career choice. J. Vocat. Behav. 2020, 120, 103448. [CrossRef]

3. Zhou, J.Y.; Li, Y.P. One step or employment first selection second? Econ. Issues Explor. 2010, 3, 187-190.

4. Akkermans, J.; Collings, D.G.; Veiga, S.P.D.M.; Post, C.; Seibert, S. Toward a broader understanding of career shocks: Exploring interdisciplinary connections with research on job search, human resource management, entrepreneurship, and diversity. J. Vocat. Behav. 2021, 126, 103563. [CrossRef]

5. Budjanovcanin, A.; Rodrigues, R.; Guest, D. A career with a heart: Exploring occupational regret. J. Manag. Psychol. 2019, 34, 156-169. [CrossRef]

6. Tian, L.; Pu, J.; Liu, Y.; Zhong, X.; Gui, S.; Song, X.; Xu, S.; Zhou, X.; Wang, H.; Zhou, W.; et al. Relationship between burnout and career choice regret among Chinese neurology postgraduates. BMC Med. Educ. 2019, 19, 162. [CrossRef]

7. Schein, E.H. Career Dynamics: Matching Individual and Organizational Needs; Addison-Wesley: Reading, MA, USA, 1978.

8. Abessolo, M.; Hirschi, A.; Rossier, J. Development and validation of a multidimensional career values questionnaire: A measure integrating work values, career orientations, and career anchors. J. Career Dev. 2021, 48, 243-259. [CrossRef]

9. Lambert, S.A.; Herbert, I.P.; Rothwell, A.T. Rethinking the Career Anchors Inventory framework with insights from a finance transformation field study. Brit. Acc. Rev. 2020, 52, 100862. [CrossRef]

10. Alhomoud, F.K.; AlGhalawin, L.; AlGofari, G.; AlDjani, W.; Ameer, A.; Alhomoud, F. Career choices and preferences of Saudi pharmacy undergraduates: A cross sectional study. Saudi Pharm. J. 2019, 27, 467-474. [CrossRef]

11. Scanlan, G.M.; Cleland, J.; Tirling, S.A.; Walker, K.; Johnston, P. Does initial postgraduate career intention and social demographics predict perceived career behaviour? A national cross-sectional survey of UK postgraduate doctors. BMJ Open $2019,9,264$. [CrossRef]

12. Costigan, R.; Gurbuz, S.; Sigri, U. Scheins career anchors: Testing factorial validity, invariance across countries, and relationship with core self-evaluations. J. Career Dev. 2018, 45, 199-214. [CrossRef]

13. Danziger, N.; Valency, R. Career anchors: Distribution and impact on job satisfaction, the Israeli case. Career Dev. Int. 2006, 11, 293-303. [CrossRef]

14. Tremblay, M.; Dahan, J.; Gianecchini, M. The mediating influence of career success in relationship between career mobility criteria, career anchors and satisfaction with organization. Pers. Rev. 2014, 43, 818-844. [CrossRef]

15. Medsker, K.L.; O'Connor, S.R. Maximizing motivation: Career fit and job characteristics. Perform. Improv. 2015, 54, 44-48. [CrossRef]

16. Ghalavandi, H.; Arbabisarjou, A.; Yarmohammadzadeh, P.; Soltanzadeh, V. Relationship between career anchors and organizational commitment among faculty members. J. Stud. Educ. 2012, 2, 58-71. [CrossRef] 
17. Schein, E.H. Career Anchors: Discovering Your Real Values; Pfeiffer\& Company: San Diego, CA, USA, 1990.

18. Taylor, J.; Joshi, K.D. Joining the crowd: The career anchors of information technology workers participating in crowdsourcing. Inf. Syst. J. 2019, 29, 641-673. [CrossRef]

19. Kubo, Y.; Hatono, Y.; Kubo, T.; Shimamoto, S.; Nakatani, J.; Burgel, B.J. Development of the career anchors scale among occupational health nurses in Japan. J. Occup. Health 2016, 58, 519-533. [CrossRef] [PubMed]

20. Feldman, D.C.; Bolino, M.C. Career within careers: Reconceptualizing the nature of career anchors and their consequences. Hum. Resour. Manag. R 1996, 6, 89-112. [CrossRef]

21. Beck, J.; Lopa, J.M.L. An exploratory application of Schein's career anchors inventory to hotel executive operating committee members. Int. J. Hosp. Manag. 2001, 20, 15-28. [CrossRef]

22. Chang, C.L.; Shen, K.N.; Wu, S. Career anchors of IT/IS personnel: A cross-culture research based on the guanxi culture theory. J. Glob. Inf. Manag. 2020, 28, 160-190. [CrossRef]

23. Gubler, M.G.M.; Biemann, T.; Tschopp, C.; Grote, G. How career anchors differentiate managerial career trajectories: A sequence analysis perspective. J. Career Dev. 2015, 42, 412-430. [CrossRef]

24. Li, L.; Zhang, L. Exploration of career planning in state-owned enterprise employees in China-Multiple career planning based on career anchor theory. J. Lanzhou Univ. Soc. Sci. 2012, 38, 86-90.

25. Arnold, J.; Coombs, C.R.; Gubler, M. Career anchors and preferences for organizational career management: A study of information technology professionals in three European countries. Int. J. Hum. Resour. Manag. 2019, 30, 3190-3222. [CrossRef]

26. Edwards, J.R. Person-job fit: A conceptual integration, literature review, and methodological critique. Int. Rev. Ind. Organ. Psychol. 1991, 6, 283-357.

27. Zhang, X.; Liu, S.Y.; Wang, W.G. Construction and practice of person-post fit model: A practical example from company. Hum. Resour. Manag. China 2014, 22, 54-60.

28. Wang, F.X.; Ren, J. Human resources optimization allocation model based on human matching for position. Technol. Innov. Manag. 2011, 32, 237-240.

29. Chuang, A.; Sackett, P.R. The perceived importance of person-job fit and person-organization fit between and within interview stages. Soc. Behav. Personal. Int. J. 2005, 33, 209-226. [CrossRef]

30. Chen, W.Y.; Hsu, B.F.; Wang, M.L. When P-J fit and P-O fit meet guanxi in a Chinese selection context. J. Technol. Manag. China 2013, 8, 174-189. [CrossRef]

31. Xin, L.; Li, M.; Tang, F.; Wang, W.; Zhao, Y.; Zheng, X. Better match, better career: Comparing the mediating effects of demandsabilities fit and needs-supplies fit between career exploration and career satisfaction. Int. J. Ment. Health Promot. 2019, 21, 59-68. [CrossRef]

32. Nutzi, M.; Trezzini, B.; Staubli, S.; Ronca, E.; Schwegler, U. An interdisciplinary approach to job matching: Developing an occupation-specific job matching tool for reintegrating persons with spinal cord injury into the labor market. Disabil. Rehabil. 2020, 42, 2359-2373. [CrossRef]

33. Nutzi, M.; Schwegler, U.; Staubli, S.; Ziegler, R.; Trezzini, B. Factors, assessments and interventions related to job matching in the vocational rehabilitation of persons with spinal cord injury. Work 2019, 64, 117-134. [CrossRef]

34. Leung, S. A comparison of psychometric properties and normality in 4-, 5-, 6-, and 11-point likert scales. J. Soc. Serv. Res. 2011, 37, 412-421. [CrossRef]

35. Nunnally, J.C. Psychometric Theory, 1st ed.; McGraw-Hill: New York, NY, USA, 1967.

36. Hong, C.; Shanshan, L. Measuring the psychological distance between an organization and its members-The construction and validation of a new scale. Front. Psychol. 2018, 8, 2296.

37. Chachadi, A.; Mahat, T.; Patil, T. Chaitra an empirical study on career anchor congruence of various professionals of north karnataka. PES Bus. Rev. 2012, 2, 1-14.

38. Kim, Y.H.; O’Brien, K.M.; Kim, H. Measuring career aspirations across cultures: Using the career aspiration scale with young korean women. J. Career Assess. 2016, 24, 573-585. [CrossRef]

39. Tuononen, T.; Lammintakanen, J.; Suominen, A.L. Career anchors of dentist leaders. Acta Odontol. Scand. 2016, 74, 487-493. [CrossRef] [PubMed]

40. Holland, J.L. Making vocational choices: A theory of vocational personalities and work environments. Brit. J. Guid. Couns. 1985, $4,143-154$.

41. Sandberg, B.; Hurmerinta, L.; Zettinig, P. Highly innovative and extremely entrepreneurial individuals: What are these rare birds made of? Eur. J. Innov. Manag. 2013, 16, 227-242. [CrossRef]

42. Wan, M.M.; Shaffer, M.A.; Singh, R.; Zhang, Y. Spoiling for a fight: A relational model of daily work-family balance satisfaction. J. Occup Organ. Psych. 2021. [CrossRef]

43. Wang, Y.; Peng, J. Work-Family conflict and depression in chinese professional women: The mediating roles of job satisfaction and life satisfaction. Int. J. Ment. Health Addict. 2017, 15, 394-406. [CrossRef] 